\title{
EVALUATING THE POTENTIAL OF DESIS TO INFER PLANT TAXONOMICAL AND FUNCTIONAL DIVERSITIES IN EUROPEAN FORESTS
}

\author{
J. Pacheco-Labrador ${ }^{1 *}$, U. Weber ${ }^{1}$, X. Ma $^{2}$, M. D. Mahecha ${ }^{3}$, N. Carvalhais ${ }^{1}$, C. Wirth ${ }^{4}$, A. Huth ${ }^{5,6,7}$, F. J. Bohn ${ }^{5}$, G. Kraemer ${ }^{3}$, \\ U. Heiden ${ }^{8}$, FunDivEUROPE members ${ }^{9}$, M. Migliavacca ${ }^{10,1}$
}

\author{
${ }^{1}$ Max Planck Institute for Biogeochemistry, Jena, Germany - (jpacheco, uweber, ncarval, mmiglia) @ bgc-jena.mpg.de \\ ${ }^{2}$ College of Earth and Environmental Sciences, Lanzhou University, Lanzhou, Gansu, China - xuanlongma.cn@ gmail.com \\ ${ }^{3}$ Remote Sensing Center for Earth System Research, University of Leipzig, Leipzig, Germany - (miguel.mahecha, guido.kraemer) \\ @ uni-leipzig.de \\ ${ }^{4}$ Systematic Botany and Functional Biodiversity, University of Leipzig, Leipzig, Germany - cwirth@uni-leipzig.de \\ ${ }_{5}^{5}$ Department of Ecological Modelling, Helmholtz Centre for Environmental Research-UFZ, Leipzig, Saxony, Germany - \\ (andreas.huth, friedrich.bohn) @ufz.de \\ ${ }^{6}$ Institute of Environmental Systems Research, University of Osnabrück, Osnabrück, Lower Saxony, Germany \\ ${ }^{7}$ German Centre for Integrative Biodiversity Research (iDiv) Halle-Jena-Leipzig, Leipzig, Saxony, Germany \\ ${ }^{8}$ Earth Observation Center (EOC), German Aerospace Center (DLR), Weßling, Germany - uta.heiden@ dlr.de \\ ${ }^{9}$ Albert-Ludwigs-Universitaet Freiburg (ALU-FR), Freiburg, Germany - michael.scherer@biologie.uni-freiburg.de \\ ${ }^{10}$ European Commission, Joint Research Centre (JRC), Ispra, Italy - mirco.migliavacca@ec.europa.eu
}

\section{Commission III WG III/4}

KEY WORDS: Functional diversity, taxonomical diversity, spectral diversity, DESIS, FunDivEUROPE.

\begin{abstract}
:
Tackling the accelerated human-induced biodiversity loss requires tools able to map biodiversity and its changes globally. Remote sensing (RS) offers unique capabilities of characterizing Earth surfaces; therefore, it could map plant biodiversity continuously and globally. This approach is supported by the Spectral Variation Hypothesis (SVH), which states that spectra and species (taxonomic and trait) diversities are linked through environmental heterogeneity. In this work, we evaluate the capability of the DESIS hyperspectral imager to capture plant diversity patterns as measured in dedicated plots of the network FunDivEUROPE. We computed functional and taxonomical diversity metrics from field taxonomic, structural, and foliar measurements in vegetation plots sampled in Spain and Romania. In addition, we also computed functional diversity metrics both from the DESIS reflectance factors and from vegetation parameters estimated via inversion of a radiative transfer model. Results showed that only metrics computed from spectral reflectance were able to capture taxonomic variability in the area. However, the lack of sensitivity was related to the insufficient plot size and the lack of spatial match between remote sensing and field data, but also the differences between the information contained in the field traits and remote sensing data, and the potential uncertainties in the remote estimates of vegetation parameters. Thus, while DESIS showed some sensitivity to plant diversity, further efforts are needed to deploy suitable biodiversity evaluation and validation plots and networks that support the development of biodiversity remote sensing products.
\end{abstract}

\section{INTRODUCTION}

The accelerated loss of biodiversity induced by human actions imposes a pressing need to develop reliable tools to monitor Earth's biodiversity (Pereira et al., 2013). Remote sensing provides global maps of multiple variables that are relevant for the study of Climate Change (GCOS, 2003), as well as major biodiversity drivers, but not of biodiversity itself (e.g., land-use change and climatic variables) (Sohl and Sleeter, 2012; Yang et al., 2013). In this context, Pereira et al. (2013) proposed that global characterization of biodiversity could be achieved by the definition, estimation, and analysis of the termed "Essential Biodiversity Variables" (EBVs). Due to their nature and influence on the optical radiation scattered by vegetation surfaces, several of these variables could be inferred by remote sensing (Hardisty et al., 2019; Jetz et al., 2019).

Alternatively, plant diversity might be directly inferred from the variability of the spectral signals captured by satellite imagers. The underlying idea is that the variability of the spectral signals is connected with plant functional and taxonomic diversities, as stated by the Spectral Variation Hypothesis (SVH) (Palmer et al., 2002). Additionally, remote sensing signals can be related to vegetation state parameters through the inversion of radiative transfer models (RTMs). These models describe the interaction of radiation with canopy structures, e.g., leaves, and known optical properties, e.g., the absorption coefficients of pigments. Some of these parameters have been proposed as EBVs (Skidmore et al., 2021). Therefore, the reflectance factors' variability and parameter estimates from those could be informative of the vegetation diversity.

Nonetheless, biodiversity is a complex term. It involves different facets of the biological variability, such as taxonomical (species), functional (functional traits, the "characteristics of an organism that are considered relevant to its response to the environment and/or its effects on ecosystem functioning" (c.f. Cabido and Díaz (2001)), or phylogenetic (the branch length of the evolutionary tree of a community). We will focus on the two first aspects. Taxonomic diversity is usually defined as a

\footnotetext{
* Corresponding author
} 
function of the species in a study area. However, functional diversity can be described with several traits, and therefore can involve multidimensional information that must be summarized in comparable quantities. This is the aim of the functional diversity metrics (FDMs). These metrics quantify different aspects of functional diversity (i.e., richness, evenness, and divergence) with a single value (Laliberté and Legendre, 2010; Mason et al., 2005; Villéger et al., 2008). A meaningful computation of FDMs typically requires removing the covariance between trait dimensions (Anderson, 2006). Otherwise, the addition of co-variated variables can spuriously inflate their value. In a remote sensing context, they can be computed both from parameter estimates, which operate as a surrogate of functional traits (Schneider et al., 2017), or directly from spectral reflectance factors replacing functional by "spectral traits" (Torresani et al., 2019). However, the potential of such approaches still needs to be understood better before they can be widely applied.

Also, the trade-offs between different sensor resolutions, methods, and metrics remain unclear. The increasing availability and the expected arrival of spaceborne hyperspectral missions (e.g., DESIS, PRISMA, EnMAP, SBG, CHIME) will provide better and detailed information of Earth surfaces in the spectral domain. Compared with multispectral imagers, these missions will enable the exploitation of narrow spectral features characteristic of certain species or traits, increase the parameter retrieval accuracy and the number of parameters that could be estimated by improving the constrain of RTMs (Goetz, 2009). In order to accelerate the exploitation of full-range hyperspectral data provided by the upcoming missions such as EnMAP, we evaluate the potential of functional diversity metrics computed from hyperspectral imagery to quantify taxonomic and functional diversity in plots of the FunDivEUROPE network (Baeten et al., 2013). These plots were established in mature European forests to characterize diversity-function relationships but not specifically for the evaluation of remote sensing products. We used DESIS imagery of similar spatial resolution and a narrower (400-1000 nm) spectral range than EnMAP.

\section{METHODS}

\subsection{FunDivEUROPE biodiversity plots}

The FunDivEUROPE network has deployed 30x30 m plots in forests where taxonomic and functional diversity were characterized from species identity, abundances, and foliar and structural traits measured in place for species accounting for more than $95 \%$ cumulative species abundance (Baeten et al., 2013; Benavides et al., 2019a; Benavides et al., 2019b). Tree height $\left(h_{c}, \mathrm{~m}\right)$, diameter at breast height $(D B H, \mathrm{~m})$, and crown cross-sectional area $\left(C C S A, \mathrm{~cm}^{2}\right)$ were measured per species. LAI was determined per plot with an LAI-2000 Plant Canopy Analyzer (LI-COR, Lincoln, NE, USA) per plot (Grossiord et al., 2014). Also, leaf nitrogen concentration ( $\left.N_{\text {mass }}, \%\right)$, leaf carbon concentration $\left(C_{\text {mass }}, \%\right)$, leaf area $\left(l_{\mathrm{a}}, \mathrm{mm}^{2}\right)$, specific leaf area $\left(S L A, \mathrm{~mm}^{2} / \mathrm{mg}\right)$, and leaf dry matter concentration (LDMC, $\mathrm{mg} / \mathrm{g}$ ) were measured per species (Benavides et al., 2019a; Benavides et al., 2019b). Measurements took place in the summer of 2013. Further information about the data available in these plots can be found in Ma et al. (2019). Not all the parameters were "functional traits" (Díaz and Cabido, 2001), but just vegetation parameters varying with environmental conditions and ontogeny (e.g., canopy height or leaf area index). Although the network expands through six European countries, only the sites of Romania and Spain were could be used in this study since DESIS imagery and foliar traits were available.

\subsection{DESIS imagery and spectral data analysis}

DESIS imagery was acquired over the FunDivEUROPE sites of Spain (2020-Jun-21, 06:51) and Romania (2020-Jun-29, 07:02), covering 19 and 15 plots in each country, respectively. DESIS L2A products were downloaded from the EOWEB® ${ }^{\circledR}$ GeoPortal (https://eoweb.dlr.de/egp/) after automated processing following DLR standard procedures (Alonso et al., 2019). 4x binned images featuring 58 bands were downloaded and clipped $250 \mathrm{~m}$ around each of the biodiversity plots. Figure 2 shows the DESIS $3 \times 3$ pixels window (blue square) extracted around one of the FunDivEUROPE plots in Spain (red-dashed square) (a) and the spectra of those pixels on the left (b). As can be seen, DESIS spatial resolution is comparable to the plot size, and the diversity metrics are computed from a larger extent where field data are sampled.
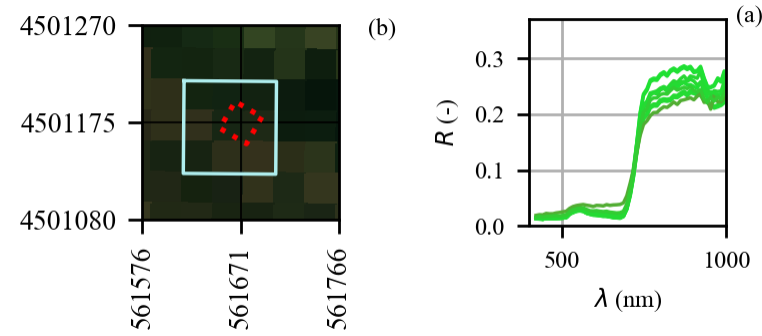

Figure 1. DESIS 3-by-3 window over a FunDivEUROPE site.

Sun zenith $\left(\theta_{\text {sun }}\right)$ and azimuth $\left(\phi_{\text {sun }}\right)$ angles and the averaged aerosol optical thickness of the scene were obtained from the imagery metadata and assumed homogeneous for all plots. View zenith $\left(\theta_{\text {view }}\right)$ and azimuth $\left(\phi_{\text {view }}\right)$ angles were provided at the center of the scene in the metadata. Knowing sensor height (also in the metadata), the position of the sensor was estimated from these angles. Knowing the scanning direction followed by the sensor, we recalculated the observation angles of each point of the image, and therefore for each plot. From these angles, sunview azimuth difference $(\Delta \phi)$ was calculated per plot (Table 1).

\begin{tabular}{|l|c|c|}
\hline & Spain & Romania \\
\hline Date & 2020-Jun-29 10:11 & 2020-Jun-29 07:02 \\
$n$ plots & 19 & 15 \\
Mean $\theta_{\text {sun }}$ & 30.8 & 45.9 \\
Mean $\theta_{\text {view }}$ & 23.8 & 2.1 \\
Mean $\Delta \phi$ & 6.6 & 3.7 \\
Mean $A O T$ & 0.266 & 0.275 \\
\hline
\end{tabular}

Table 1. DESIS imagery.

\subsection{Retrieval of vegetation parameters}

In order to calculate functional diversity metrics from estimates of vegetation parameters, we constrained an RTM with DESIS reflectance factors within a 3-by-3 pixel window centered on each plot. Vegetation parameters were retrieved by inverting the optical RTM of the model SCOPE (van der Tol et al., 2009). In addition, to fit the observed reflectance factors, soil parameters of the SCOPE's model BSM were also estimated (Table 2). 


\begin{tabular}{|c|c|c|c|}
\hline Parameter & $\begin{array}{l}\text { Symb } \\
\text { ol }\end{array}$ & Units & Bounds \\
\hline \multicolumn{4}{|c|}{ Vegetation Parameters $\left(\boldsymbol{P}_{\mathrm{RTM}}\right)$} \\
\hline Leaf chlorophyll content & $C_{\mathrm{ab}}$ & $\mu \mathrm{g} \mathrm{cm}^{-2}$ & {$[0,100]$} \\
\hline Leaf carotenoids content & $C_{\text {ca }}$ & $\mu \mathrm{g} \mathrm{cm}^{-2}$ & {$[0,25]$} \\
\hline Leaf anthocyanins content & $C_{\text {ant }}$ & $\mu \mathrm{g} \mathrm{cm}-2$ & {$[0,10]$} \\
\hline Leaf senescent pigments & $C_{\mathrm{s}}$ & a.u. & {$[0,1]$} \\
\hline Leaf water content & $C_{\mathrm{w}}$ & $\mathrm{g} \mathrm{cm}^{-2}$ & $\begin{array}{l}{[0.004,} \\
0.045]\end{array}$ \\
\hline Leaf dry matter content & $C_{\mathrm{dm}}$ & $\mathrm{g} \mathrm{cm}^{-2}$ & $\begin{array}{l}{[0.00190,} \\
0.01570]\end{array}$ \\
\hline Leaf structural param. & $N$ & layers & {$[1,3]$} \\
\hline Leaf area index & $L A I$ & $m^{2} m^{-2}$ & {$[0,8]$} \\
\hline Leaf inclination param. & $L I D F_{\mathrm{a}}$ & - & {$[-1,1]$} \\
\hline Leaf inclination param. & $L I D F_{\mathrm{b}}$ & - & {$[-1,1]$} \\
\hline Canopy height & $h_{\mathrm{c}}$ & $\mathrm{M}$ & {$[0.1,10.0]$} \\
\hline Leaf width & $l_{\mathrm{qw}}$ & M & {$[0.01,0.1]$} \\
\hline \multicolumn{4}{|c|}{ Soil Parameters (BSM model) } \\
\hline Soil brightness & $B$ & - & {$[0.5,1.0]$} \\
\hline Spectral shape latitude & Lat & Deg & {$[20,40]$} \\
\hline Spectral shape longitude & Lon & Deg & {$[45,65]$} \\
\hline Soil moisture capacity & SMC & $\%$ & {$[5,55]$} \\
\hline Soil moisture content & Lat & - & {$[0,1]$} \\
\hline
\end{tabular}

Table 2. Retrieved SCOPE parameters.

The inversion took place in two steps. First, a solution was set for each pixel using an emulator of the SCOPE model trained with a dataset of 6000 synthetic samples generated using Latin Hypercube Sampling (McKay et al., 1979). The emulator was trained using the Python module scikit-learn (Pedregosa et al., 2011). Its performance was evaluated with a validation dataset of 1000 samples (Table 3). The emulator's performance was assessed using the root mean squared error $(R M S E)$ and the relative root mean squared error (RRMSE).

\begin{tabular}{|l|c|c|}
\hline & Training & Validation \\
\hline$n$ samples & 6000 & 1000 \\
RMSE $(-)$ & 0.0050 & 0.0056 \\
RRMSE $(\%)$ & 5.92 & 6.59 \\
\hline
\end{tabular}

Table 3. Emulator training and validation synthetic sample sizes and performance statistics.

We averaged soil parameters per plot in a second step, assuming little variability within the $90 \mathrm{~m}$ x $90 \mathrm{~m}$ region analyzed. Then, the vegetation parameters only were optimized minimizing a regularized cost function (Eq. 1) with the trust-region-reflective algorithm (Coleman and $\mathrm{Li}, 1996)$ implemented in the Matlab ${ }^{\mathrm{TM}}$ function lsqnonlin (MathWorks, Natick, MA, USA)

$$
\begin{gathered}
x^{2}=\sum_{\lambda}\left(R_{\text {l.pred }}-R_{\text {liobs }}\right)^{2}+\left(\gamma_{1}\left(\frac{C_{\text {ca }}}{C_{\mathrm{ab}}}-0.20\right)\right)^{2}+ \\
\left(\gamma_{2} C_{\text {ant }}\right)^{2}+\left(\gamma_{a} L A I_{\text {reg }}\right)^{2}
\end{gathered}
$$

where $\quad \chi^{2}=$ Cost function error

$R_{\lambda, \text { pred }}=$ Predicted spectral reflectance factor

$R_{\lambda, \text { obs }}=$ Observed spectral reflectance factor

$\gamma_{1}=10^{-1}$

$\gamma_{2}=10^{-2}$

$\gamma_{3}=5 \cdot 10^{-3}$ in Romania or $4 \cdot 10^{-3}$ in Spain

$L A I=L A I$ in Spain and $\mid$ LAI-6.0| in Romania

\subsection{Taxonomic and functional diversity metrics}

We computed per plot Species Richness ( $S$, number of species in each plot) and the Shannon index (H, Eq. 2) from the taxonomic data in FunDivEurope plots. The Shannon index is defined as

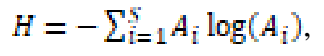

where $\quad S=$ Species Richness or number of species

$A=$ relative species abundance

We also computed Rao's $Q$ parametric indices of order $\alpha$ $\left(R a o Q_{\alpha}\right.$, Eq. 3) ranging between 0 and infinity (Rocchini et al., 2021):

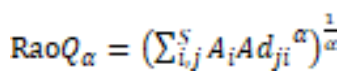

where $\quad d=$ distance metric, in this case, Euclidean

$\alpha=$ parameter weighting the roles of the distance

metric.

$R a o Q_{\alpha}$. was also computed for the reflectance factors and the vegetation parameters estimated from those. In fact, we computed Rao's $Q$ parametric indices on the components of a Principal Components Analysis (PCA) applied on these traits after standardization.

For the spectral variables (reflectance factors and parameters), we computed as well the metrics implemented in the $d b F D$ package (Laliberté and Legendre, 2010). The $d b F D$ package applies standardization and Principal Coordinates Analysis (PCoA) to the distance matrix (not the traits). The package provides: Functional Richness (FRic), which is the volume of the multidimensional convex-hull; Functional Evenness (FEve), which describes the uniformity of the abundances of the traits; Functional Divergence (FDiv), which represents the degree of divergence of the traits; Functional Dispersion (FDis), which is the weighted average distance to the centroid of the multidimensional space; and $\operatorname{Rao} Q$ which describes the weighted mean distance between traits (or $\alpha=1$ in Eq. 3).

\section{RESULTS}

\subsection{Estimation of vegetation biophysical parameters}

Some of the vegetation parameters estimated via radiative transfer inversion could be evaluated using field measurements. Figure 2 compares the estimated leaf area index (LAI, Figure $2 \mathrm{a})$ and leaf dry matter content $\left(C_{\mathrm{dm}}\right.$, Figure $\left.2 \mathrm{c}\right)$. No chlorophyll content measurements were available; therefore, we compared chlorophyll content retrievals $\left(C_{\mathrm{ab}}\right)$ with leaf nitrogen concentration ( $N_{\text {mass }}$, Figure $2 \mathrm{~b}$ ). The evaluation was performed with the coefficient of determination $\left(R^{2}\right)$, and the relative root mean squared error (RRMSE). Statistics show that the retrieval of $L A I$ was most problematic in the sites of Romania $\left(R^{2}=\right.$ 0.07). In Spain $L A I$ values were slightly higher but correlated with field observations $\left(R^{2}=0.49\right)$. Altogether, $L A I$ estimates correlated with field measurements with $R^{2}=0.56$. $C_{\mathrm{ab}}$ retrievals showed low correlations with $N_{\text {mass }}$, the highest $R^{2}$ was found in Romania (0.29). All the sites together presented a low correlation $\left(R^{2}=0.07\right)$ and an RRMSE of around $30 \%$. Dry matter content estimates showed larger values than field measurements. Correlations were higher for the Spanish $\left(R^{2}=\right.$ $0.42)$ than for the Romanian sites $\left(R^{2}=0.13\right)$ and became higher when both sites were compared together $\left(R^{2}=0.46\right)$. 

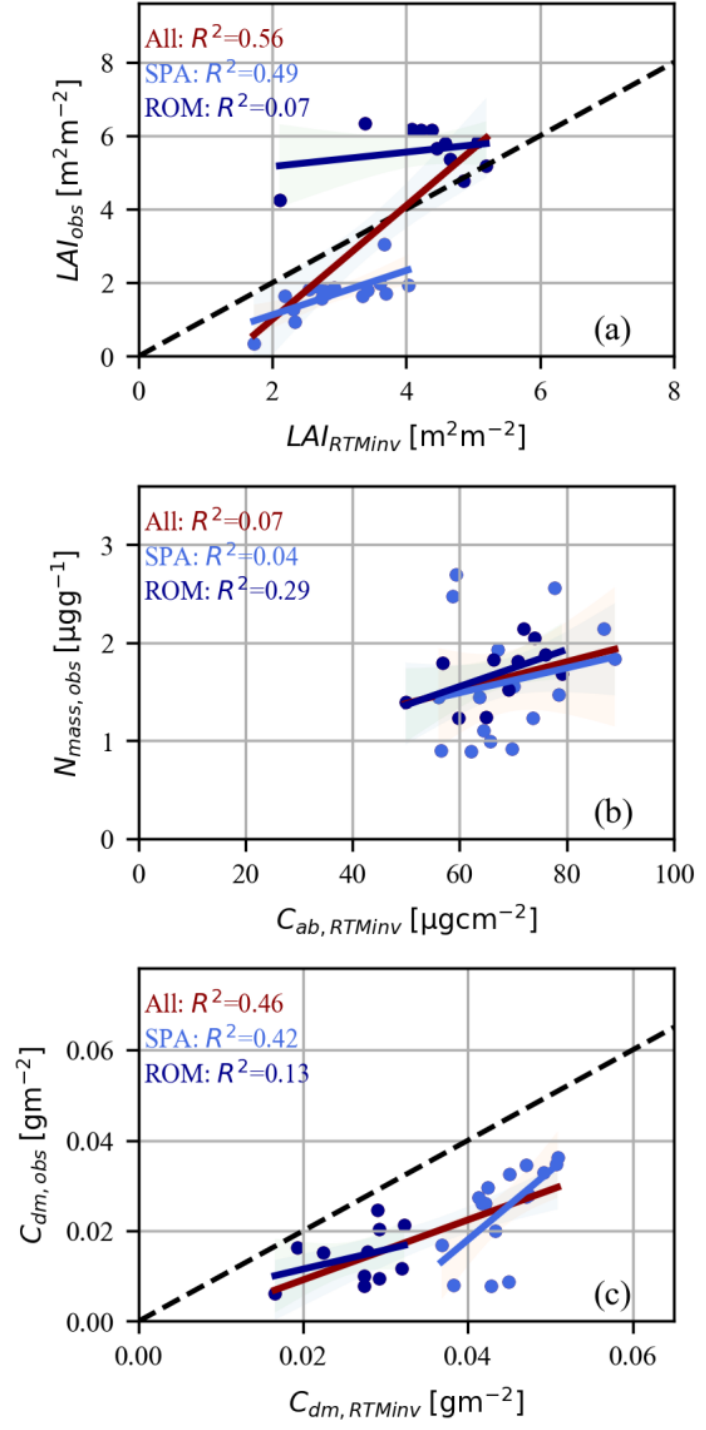

Figure 2. Evaluation of estimated parameters (subscript "RTMinv") with field measurements (subscript "obs").

\subsection{Relationships between functional diversity metrics}

Figure 3 shows the Pearson correlation coefficient $(r)$ between the taxonomical and functional diversity metrics computed from field data and the functional diversity metrics computed from DESIS imagery computed either using the $d b F D$ package (a) or following Rocchini et al. (2021) (b). Functional Richness (FRic), Evenness (FEve), and Divergence (FDiv) computed from reflectance factors are not significantly related to field diversity metrics, and in some cases, the relationships are negative. Only Functional Diversity (FDis) and some of the Rao's $Q$ parametric formulations achieve significant relationships with field taxonomical metrics, mostly with $S$. Maximum Pearson correlation coefficients were 0.53 for the $d b F D$ package metrics (Figure $3 \mathrm{a}$ ) and 0.48 for the parametric Rao's $Q$ (Figure 3b).

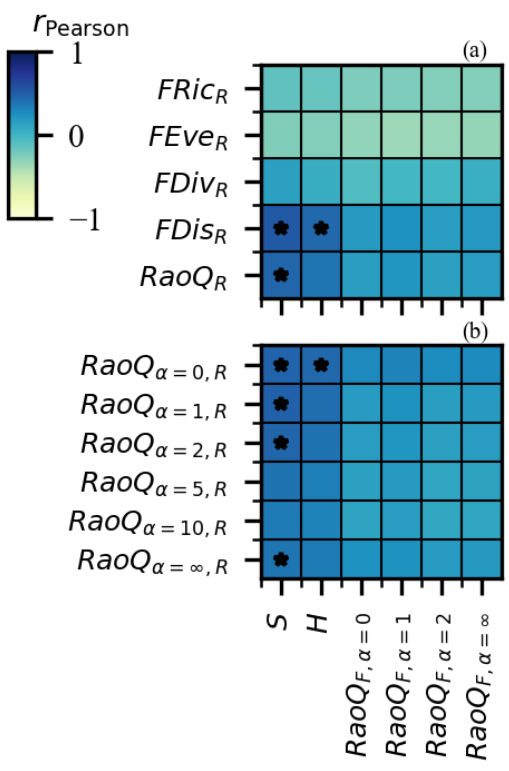

Figure 3. Pearson correlation between field and remote sensing (reflectance factors-based) metrics. Asterisks indicate significant relationships at $95 \%$ of confidence.

Functional diversity metrics computed from the vegetation parameter estimates (Figure 4) obtained via RTM inversion showed no significant correlations with field functional or taxonomical metrics. Still, similar patterns of correlation than those observed for reflectance factors-based metrics (Figure 3), except for FRic, which presents relatively stronger correlations than FEve or FDiv this time. Maximum Pearson correlation coefficients were 0.53 for the $d b F D$ package metrics (Figure $4 \mathrm{a}$ ) and 0.48 for the parametric Rao's $Q$ indices (Figure $4 \mathrm{~b}$ ).

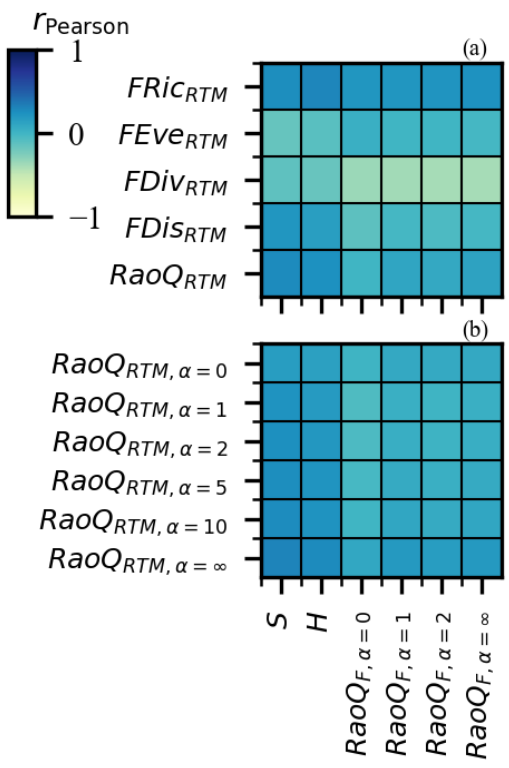

Figure 4. Pearson correlation between field and remote sensing (parameter estimate-based) metrics. Asterisks indicate significant relationships at $95 \%$ of confidence. 


\section{DISCUSSION}

The direct comparison of DESIS functional diversity metrics with field taxonomical and functional diversity metrics led to a few weak but significant linear relationships, mainly with the taxonomical indices. Comparing remote sensing estimates of plant functional diversity with field data was challenging for several reasons that might explain the limited number of significant correlations found.

First, the fact that field plot size equals the spatial resolution of the remote sensor, which forced us to compare information from different extents (the surroundings of the field plot). Taxonomical metrics are better correlated with remote sensing information than functional diversity metrics, especially when species abundance is ignored (i.e., species richness, $S$ ). We hypothesize that if the species richness does not change in the surroundings of the FunDivEUROPE plots (there is the same number of species but with different abundances), functional richness inside the plot could still correlate with spectral variability, even if the sensor cannot discriminate the individual species or their abundances. Ideally, field plots should be large enough to include several remote sensing pixels in biodiversity applications.

A second potential source of uncertainty is the temporal mismatch between field and remote sensing samplings ( 8 years, but taking place in the same season). However, Ma et al. (2019) proved that FunDivEUROPE plots are relatively stable in time. They analyzed remote sensing data time series and found that spectral information was comparable between different years at the same phenological stages. These results are coherent with the design of the FunDivEUROPE experiment. The plots were located in mature and stable forests not subject to management nor human exploitation (Baeten et al., 2013), minimizing thus the effect of temporal mismatches. Based on these results, we assumed that data acquired within the same phenological stage in different years should still be comparable if no major disturbance occurred. Still, some inter-annual variability in the functional traits and eventual tree mortality might account for some unexplained variance.

A third potential source of uncertainty is the mismatch between the information contained in the vegetation and traits compared. The traits sampled in the field were selected to perform ecological studies to analyze the relationships between function and biodiversity. On the contrary, vegetation parameters estimated from remote sensing are limited to traits describing light-matter interaction in an RTM, independently of their ecological significance. Correlations can exist between these parameters. For example, field structural parameters are usually related to leaf area index by allometric equations (Fischer et al., 2019; Turner et al., 2000), nitrogen relates with chlorophyll content (Evans and Clarke, 2019; Li et al., 2019), and with specific leaf area (Reich, 2014; Wright et al., 2004). Therefore, spectral variability and the variability of parameters estimated remotely might be explained by traits of ecological significance. Still, the interspecific variability of these radiative transfer and ecological parameters might induce some uncertainty.

The fourth challenge in the comparison of remote sensing and field estimates of vegetation diversity is the presence of uncertainties in the remote sensing signals (they exist in the field data as well). Uncertainty in the reflectance propagates to the retrieval of vegetation parameters, which adds to the uncertainties associated with the model estimation process (Beven, 2006). Also, the retrieval of vegetation parameters is affected by the model's inaccuracies. The use of more complex and detailed RTMs might have provided more accurate estimates of vegetation parameters. These facts might explain the absence of significant relationships found in the metrics computed from the parameter estimates. For example, comparing these estimates with field data showed medium and low correlations (Figure 2).

The abovementioned sources of uncertainty prevent evaluating the potential of spaceborne hyperspectral imagers to infer plant functional diversity from space. Part of these uncertainties relates to the fact that biodiversity monitoring sites and networks have not usually considered the need to support remote sensing studies. On the one hand, biodiversity plots should be at least three times larger than the spatial resolution of hyperspectral imagers so that their variability can be characterized with 3-by-3 windows in the imagery. On the other hand, field surveys should also measure variables that control the spectral signals captured by these sensors (i.e., radiative transfer parameters), enabling a sounder comparison with spectral variability. Collaboration between ecologists and the remote sensing community should be enhanced to develop new satellite products that describe plant functional diversity on a global scale.

Also, our analysis does not fully cover the optical domain. Several authors have identified the short-wave infrared (SWIR) region as valuable insight on relevant leaf traits such as specific leaf area (one of the traits sampled in the FunDivEUROPE plots), among others (Cavender-Bares et al., 2020). We hypothesize that hyperspectral imagers covering the SWIR region, such as EnMAP, could improve the monitoring of plant functional diversity from space and effectively enable alternative methods based on the variability of estimated plant traits (Schneider et al., 2017). Other remote sensing techniques, such as Radar and Lidar have recently proven potential to assess plant biodiversity (Bae et al., 2019) could be combined with optical data to improve plant biodiversity characterization Further work with suitable datasets is needed to understand how plant trait diversity propagates to spectral diversity, how remote sensing can infer the first using different missions and metrics.

\section{ACKNOWLEDGEMENTS}

The authors acknowledge the German Aerospace Center (DLR) project OBEF-Accross2 "The Potential of Earth Observations to Capture Patterns of Biodiversity" (Contract No. 50EE1912, German Aerospace Center). The authors acknowledge the German Aerospace Center (DLR) for providing DESIS imagery through the Announcement of Opportunity "EBioIDEA: Enhancing Biodiversity Inventories with DESIS Imagery Analysis". FunDivEUROPE data collection was supported by the European Union Seventh Framework Programme (FP7/2007-2013) (grant agreement number: 265171) and the EU H2020 project Soil4Europe (Bioidversa 2017-2019). The in-situ plant traits data collected over Romanian and Spanish sites were supported by a Marie-Curie Fellowship (DIVERFOR, FP7-PEOPLE-2011-IEF. No. 302445) to Dr. Raquel Benavides. We thank Prof. Dr. Michael SchererLorenzen for coordinating the interaction with the FunDivEUROPE network and Dr. Raquel. Benavides, Dr. Olivier Bouriaud, Dr. Ionut Barnoaiea, Dr. Fernando Valladares for the coordination and acquisition of field data in FunDivEUROPE.

\section{REFERENCES}

Alonso, K., Bachmann, M., Burch, K., Carmona, E., Cerra, D., de los Reyes, R., Dietrich, D., Heiden, U., Hölderlin, A., Ickes, J., Knodt, U., Krutz, D., Lester, H., Müller, R., Pagnutti, M., 
Reinartz, P., Richter, R., Ryan, R., Sebastian, I., Tegler, M., 2019. Data Products, Quality and Validation of the DLR Earth Sensing Imaging Spectrometer (DESIS). Sensors 19, 4471 Anderson, M.J., 2006. Distance-Based Tests for Homogeneity of Multivariate Dispersions. Biometrics 62, 245-253.

Bae, S., Levick, S.R., Heidrich, L., Magdon, P., Leutner, B.F., Wöllauer, S., Serebryanyk, A., Nauss, T., Krzystek, P., Gossner, M.M., Schall, P., Heibl, C., Bässler, C., Doerfler, I., Schulze, E.-D., Krah, F.-S., Culmsee, H., Jung, K., Heurich, M., Fischer, M., Seibold, S., Thorn, S., Gerlach, T., Hothorn, T., Weisser, W.W., Müller, J., 2019. Radar vision in the mapping of forest biodiversity from space. Nature Communications 10, 4757.

Baeten, L., Verheyen, K., Wirth, C., Bruelheide, H., Bussotti, F., Finér, L., Jaroszewicz, B., Selvi, F., Valladares, F., Allan, E., Ampoorter, E., Auge, H., Avăcăriei, D., Barbaro, L., Bărnoaiea, I., Bastias, C.C., Bauhus, J., Beinhoff, C., Benavides, R., Benneter, A., Berger, S., Berthold, F., Boberg, J., Bonal, D., Brüggemann, W., Carnol, M., Castagneyrol, B., Charbonnier, Y., Chećko, E., Coomes, D., Coppi, A., Dalmaris, E., Dănilă, G., Dawud, S.M., de Vries, W., De Wandeler, H., Deconchat, M., Domisch, T., Duduman, G., Fischer, M., Fotelli, M., Gessler, A., Gimeno, T.E., Granier, A., Grossiord, C., Guyot, V., Hantsch, L., Hättenschwiler, S., Hector, A., Hermy, M., Holland, V., Jactel, H., Joly, F.-X., Jucker, T., Kolb, S., Koricheva, J., Lexer, M.J., Liebergesell, M., Milligan, H., Müller, S., Muys, B., Nguyen, D., Nichiforel, L., Pollastrini, M., Proulx, R., Rabasa, S., Radoglou, K., Ratcliffe, S., Raulund-Rasmussen, K., Seiferling, I., Stenlid, J., Vesterdal, L., von Wilpert, K., Zavala, M.A., Zielinski, D., Scherer-Lorenzen, M., 2013. A novel comparative research platform designed to determine the functional significance of tree species diversity in European forests. Perspectives in Plant Ecology, Evolution and Systematics 15, 281-291.

Benavides, R., Scherer-Lorenzen, M., Valladares, F., 2019a. The functional trait space of tree species is influenced by the species richness of the canopy and the type of forest. Oikos 128 , 1435-1445.

Benavides, R., Valladares, F., Wirth, C., Müller, S., SchererLorenzen, M., 2019b. Intraspecific trait variability of trees is related to canopy species richness in European forests. Perspectives in Plant Ecology, Evolution and Systematics 36, 24-32.

Beven, K., 2006. A manifesto for the equifinality thesis. Journal of Hydrology 320, 18-36.

Cavender-Bares, J., Schweiger, A.K., Pinto-Ledezma, J.N., Meireles, J.E., 2020. Applying Remote Sensing to Biodiversity Science, in: Cavender-Bares, J., Gamon, J.A., Townsend, P.A. (Eds.), Remote Sensing of Plant Biodiversity. Springer International Publishing, Cham, pp. 13-42.

Coleman, T.F., Li, Y., 1996. An Interior Trust Region Approach for Nonlinear Minimization Subject to Bounds. SIAM Journal on Optimization 6, 418-445.

Díaz, S., Cabido, M., 2001. Vive la différence: plant functional diversity matters to ecosystem processes. Trends in Ecology \& Evolution 16, 646-655.

Evans, J.R., Clarke, V.C., 2019. The nitrogen cost of photosynthesis. Journal of Experimental Botany 70, 7-15.

Fischer, F.J., Maréchaux, I., Chave, J., 2019. Improving plant allometry by fusing forest models and remote sensing. New Phytologist 223, 1159-1165.

GCOS, 2003. The second report on the adequacy of the global observing systems for climate in support of the UNFCCC, GCOS Report. World Meteorological Organization, Geneva, Switzerland, p. 73.
Goetz, A.F.H., 2009. Three decades of hyperspectral remote sensing of the Earth: A personal view. Remote Sensing of Environment 113, S5-S16.

Grossiord, C., Granier, A., Ratcliffe, S., Bouriaud, O., Bruelheide, H., Chećko, E., Forrester, D.I., Dawud, S.M., Finér, L., Pollastrini, M., Scherer-Lorenzen, M., Valladares, F., Bonal, D., Gessler, A., 2014. Tree diversity does not always improve resistance of forest ecosystems to drought. Proceedings of the National Academy of Sciences 111, 14812.

Hardisty, A.R., Michener, W.K., Agosti, D., Alonso García, E., Bastin, L., Belbin, L., Bowser, A., Buttigieg, P.L., Canhos, D.A.L., Egloff, W., De Giovanni, R., Figueira, R., Groom, Q., Guralnick, R.P., Hobern, D., Hugo, W., Koureas, D., Ji, L., Los, W., Manuel, J., Manset, D., Poelen, J., Saarenmaa, H., Schigel, D., Uhlir, P.F., Kissling, W.D., 2019. The Bari Manifesto: An interoperability framework for essential biodiversity variables. Ecological Informatics 49, 22-31.

Jetz, W., McGeoch, M.A., Guralnick, R., Ferrier, S., Beck, J., Costello, M.J., Fernandez, M., Geller, G.N., Keil, P., Merow, C., Meyer, C., Muller-Karger, F.E., Pereira, H.M., Regan, E.C., Schmeller, D.S., Turak, E., 2019. Essential biodiversity variables for mapping and monitoring species populations. Nature Ecology \& Evolution 3, 539-551.

Laliberté, E., Legendre, P., 2010. A distance-based framework for measuring functional diversity from multiple traits. Ecology 91, 299-305.

Li, Y., Song, H., Zhou, L., Xu, Z., Zhou, G., 2019. Vertical distributions of chlorophyll and nitrogen and their associations with photosynthesis under drought and rewatering regimes in a maize field. Agricultural and Forest Meteorology 272-273, 4054.

Ma, X., Mahecha, M.D., Migliavacca, M., van der Plas, F., Benavides, R., Ratcliffe, S., Kattge, J., Richter, R., Musavi, T., Baeten, L., Barnoaiea, I., Bohn, F.J., Bouriaud, O., Bussotti, F., Coppi, A., Domisch, T., Huth, A., Jaroszewicz, B., Joswig, J., Pabon-Moreno, D.E., Papale, D., Selvi, F., Laurin, G.V., Valladares, F., Reichstein, M., Wirth, C., 2019. Inferring plant functional diversity from space: the potential of Sentinel-2. Remote Sensing of Environment 233, 111368.

Mason, N.W.H., Mouillot, D., Lee, W.G., Wilson, J.B., 2005 Functional richness, functional evenness and functional divergence: the primary components of functional diversity. Oikos 111, 112-118.

McKay, M.D., Beckman, R.J., Conover, W.J., 1979. A Comparison of Three Methods for Selecting Values of Input Variables in the Analysis of Output from a Computer Code. Technometrics 21, 239-245.

Palmer, M.W., Earls, P.G., Hoagland, B.W., White, P.S., Wohlgemuth, T., 2002. Quantitative tools for perfecting species lists. Environmetrics 13, 121-137.

Pedregosa, F., Varoquaux, G., Gramfort, A., Michel, V., Thirion, B., Grisel, O., Blondel, M., Prettenhofer, P., Weiss, R., Dubourg, V., Vanderplas, J., Passos, A., Cournapeau, D., Brucher, M., Perrot, M., Duchesnay, É., 2011. Scikit-learn: Machine Learning in Python. Journal of Machine Learning Research 12, 2825-2830.

Pereira, H.M., Ferrier, S., Walters, M., Geller, G.N., Jongman, R.H.G., Scholes, R.J., Bruford, M.W., Brummitt, N., Butchart, S.H.M., Cardoso, A.C., Coops, N.C., Dulloo, E., Faith, D.P., Freyhof, J., Gregory, R.D., Heip, C., Höft, R., Hurtt, G., Jetz, W., Karp, D.S., McGeoch, M.A., Obura, D., Onoda, Y., Pettorelli, N., Reyers, B., Sayre, R., Scharlemann, J.P.W., Stuart, S.N., Turak, E., Walpole, M., Wegmann, M., 2013. Essential Biodiversity Variables. Science 339, 277.

Reich, P.B., 2014. The world-wide 'fast-slow' plant economics spectrum: a traits manifesto. Journal of Ecology 102, 275-301. 
Rocchini, D., Marcantonio, M., Da Re, D., Bacaro, G., Feoli, E., Foody, G.M., Furrer, R., Harrigan, R.J., Kleijn, D., Iannacito, M., Lenoir, J., Lin, M., Malavasi, M., Marchetto, E., Meyer, R.S., Moudry, V., Schneider, F.D., Š́mová, P., Thornhill, A.H., Thouverai, E., Vicario, S., Wayne, R.K., Ricotta, C., 2021. From zero to infinity: Minimum to maximum diversity of the planet by spatio-parametric Rao's quadratic entropy. Global Ecology and Biogeography 30, 1153-1162.

Schneider, F.D., Morsdorf, F., Schmid, B., Petchey, O.L., Hueni, A., Schimel, D.S., Schaepman, M.E., 2017. Mapping functional diversity from remotely sensed morphological and physiological forest traits. Nature Communications 8, 1441.

Skidmore, A.K., Coops, N.C., Neinavaz, E., Ali, A., Schaepman, M.E., Paganini, M., Kissling, W.D., Vihervaara, P., Darvishzadeh, R., Feilhauer, H., Fernandez, M., Fernández, N., Gorelick, N., Geijzendorffer, I., Heiden, U., Heurich, M., Hobern, D., Holzwarth, S., Muller-Karger, F.E., Van De Kerchove, R., Lausch, A., Leitão, P.J., Lock, M.C., Mücher, C.A., O’Connor, B., Rocchini, D., Roeoesli, C., Turner, W., Vis, J.K., Wang, T., Wegmann, M., Wingate, V., 2021. Priority list of biodiversity metrics to observe from space. Nature Ecology \& Evolution 5, 896-906.

Sohl, T., Sleeter, B., 2012. Role of Remote Sensing for LandUse and Land-Cover Change Modeling, in: Giri, C.P. (Ed.), Remote sensing of land use and land cover: principles and applications. CRC Press, Boca Raton, FL, pp. 225-239.

Torresani, M., Rocchini, D., Sonnenschein, R., Zebisch, M., Marcantonio, M., Ricotta, C., Tonon, G., 2019. Estimating tree species diversity from space in an alpine conifer forest: The Rao's Q diversity index meets the spectral variation hypothesis. Ecological Informatics 52, 26-34.

Turner, D.P., Acker, S.A., Means, J.E., Garman, S.L., 2000. Assessing alternative allometric algorithms for estimating leaf area of Douglas-fir trees and stands. Forest Ecology and Management 126, 61-76.

van der Tol, C., Verhoef, W., Timmermans, J., Verhoef, A., Su, Z., 2009. An integrated model of soil-canopy spectral radiances, photosynthesis, fluorescence, temperature and energy balance. Biogeosciences 6, 3109-3129.

Villéger, S., Mason, N.W.H., Mouillot, D., 2008. New multidimensional functional diversity indices for a multifaceted framework in functional ecology. Ecology 89, 2290-2301.

Wright, I.J., Reich, P.B., Westoby, M., Ackerly, D.D., Baruch, Z., Bongers, F., Cavender-Bares, J., Chapin, T., Cornelissen, J.H.C., Diemer, M., Flexas, J., Garnier, E., Groom, P.K., Gulias, J., Hikosaka, K., Lamont, B.B., Lee, T., Lee, W., Lusk, C., Midgley, J.J., Navas, M.-L., Niinemets, Ü., Oleksyn, J., Osada, N., Poorter, H., Poot, P., Prior, L., Pyankov, V.I., Roumet, C., Thomas, S.C., Tjoelker, M.G., Veneklaas, E.J., Villar, R., 2004. The worldwide leaf economics spectrum. Nature 428, 821.

Yang, J., Gong, P., Fu, R., Zhang, M., Chen, J., Liang, S., Xu, B., Shi, J., Dickinson, R., 2013. The role of satellite remote sensing in climate change studies. Nature Climate Change 3, 875-883. 